\title{
A Lei de Peter *
}

EXPLICAÇÃO DA INCOMPETENCIA OCUPACIONAL

LAURENCE J. PETER

Professor associado da Universidade de

Educação da Califórnia do Sul

e

RAYMOND HULL

TRADUÇÃO DE MARQUES DE OLIVEIRA

A incompetência ocupacional está em tôda parte. Você já notou? Provàvelmente todos nós já o percebemos.

Vemos políticos indecisos posando como estadistas resolutos e "fontes autorizadas" que culpam "imponderáveis situacionais" por suas desinformações. São sem limite os funcionários públicos indolentes e insolentes, os comandantes militares cuja timidez de comportamento desmente sua retórica encouraçada, e governadores cuja servilidade inata os impede de governar efetivamente. $\mathrm{Na}$ nossa afetação, pràticamente damos de ombros ao clérigo imoral, ao juiz corrupto, ao promotor incoerente, ao autor que não sabe escrever $e$ ao professor de português que não sabe soletrar. Nas Universidades vemos proclamações assinadas por administradores cujas próprias comunicações internas são irremediàvelmente confusas, e aulas zumbidas por instrutores inaudiveis ou incompreensiveis.

Vendo incompetência em todos os niveis de tôda hierarquia - política, legal, educacional e industrial - levantei a hipótese de que a causa fôsse alguma característica inerente às regras que governam a colocação dos empregados. Assim começou meu estudo sério dos caminhos pelos quais os empregados sobem na hierarquia e do que acontece a êles depois da promoção.

Para meus dados científicos foram colhidas centenas de histórias de casos. Eis exemplos típicos.

\section{Arquivo de Administração}

Municipal, caso n? 17.

J. S. Minion era chefe de manutenção no Departamento de Obras Públicas da Cidade Excelsio. Era favorito dos funcionários mais antigos da Prefeitura. Todos louvavam sua afabilidade permanente.

"Gosto do Minion", disse o superintendente das obras. "Ele tem juizo e é sempre agradável e cordato."

Êste comportamento era apropriado para a posiçăo de Minion: não era obrigado a planejar nada, portanto, não tinha necessidade de discordar de seus superiores.

O superintendente de obras aposentou-se e Minion sucedeu-o. Minion

* (Management Review, 1969, Vol. 58, n. 2) American Management Association, Inc. 
continuou a concordar com todos. Passava ao seu capataz tôdas as sugestões que vinham de cima. Os conflitos conseqüentes quanto ao planejamento, e a contínua mudança de planos, logo desmoralizaram o Departamento. Choveram reclamações do Prefeito e de outros funcionários, dos contribuintes e do sindicato dos trabalhadores na manutenção.

Minion ainda diz "sim" a todo mundo, e leva mensagens solertemente para cima e para baixo entre seus superiores e seus subordinados. Nominalmente superintendente, na verdade faz o papel de mensageiro. O Departamento de Manutenção ultrapassa periòdicamente o orçamento, mas êle não consegue cumprir seu programa de trabalho. Em resumo, Minion, capataz competente, tornou-se superintendente incompetente.

\section{Arquivo das Indústrias}

de Serviço, caso n? 3.

E. Tinker era excepcionalmente zeloso e inteligente como aprendiz na G. Reece Auto Repair, Inc. e breve elevou-se a mecânico diarista. No seu serviço mostrou excepcional habilidade no diagnosticar falhas ocultas e paciência infinita no corrigi-las. Foi promovido a chefe da oficina mecânica.

Mas aí seu amor por coisas mecânicas e seu perfeicionismo transformamse em desvantagens. Êle empreenderá qualquer trabalho que julgar interessante, não importando quão cheia de serviço esteja a casa. "Nós resolveremos isto de qualquer jeito", diz.

Não dá por terminado um serviço enquanto não estiver inteiramente satisfeito com o mesmo.
Está sempre se intrometendo, raramente é encontrado na sua escrivaninha. Quase sempre está muito ocupado com um motor aberto $e$, enquanto o homem que deveria estar fazendo o serviço fica observando, outros operários sentam-se em volta, esperando que Ihes sejam dadas novas incumbências. Como resultado, a oficina fica abarrotada de serviço, sempre em confusão, e o prazo de entrega freqüentemente não é cumprido.

Tinker não pode entender que o cliente comum pouco se importa com perfeição mas - quer seu carro de volta a tempo! Êle não pode compreender que muitos dos seus homens estão menos interessados em motores que nos cheques de pagamento. Por isso Tinker não pode darse bem nem com seus fregueses, nem com seus subordinados. Era um mecânico competente mas agora é um chefe de oficina incompetente.

Com o tempo vi que todos êstes casos tinham uma característica comum. O empregado tinha sido promovido de uma posição de competência para uma de incompetência. Vi que, mais cedo ou mais tarde, isto poderia acontecer a todos os empregados em tôdas as hierarquias.

\section{Arquivo de Casos}

\section{Hipotéticos, caso no 1.}

Imagine sua própria fábrica de enrolar pilulas, Pilula Perfeita Ltda. Seu mestre enrolador de pílulas morre de úlcera perfurada. Você precisa de uma substituição. Naturalmente, você olha para a tropa de enroladores de pilulas.

A senhorita Oval, d. Elípse, o sr. Cilindro $\theta$ o sr. Cubo, todos mostram 
vários graus de incompetência. Serão, naturalmente, inelegíveis para promoção. Você escolherá - se tudo o mais estiver em pé de igualdade - seu enrolador de pílulas, mais competente, o Sr. Círculo, e promovê-lo-á a mestre.

Suponha agora que o sr. Círculo se demonstre competente como mestre. Mais tarde, quando seu mestre-geral, Legree, fôr elevado a Gerente de Produção, o sr. Círculo será escolhido para ocupar o lugar dêle.

Se, por outro lado, o sr. Círculo fôr um mestre incompetente, não obterá mais promoção. Terá alcançado o que eu chamo de seu "nível de incompetência". Lá permanecerá até o fim de sua carreira.

Alguns empregados, como o sr. Cllindro ou o sr. Cubo, atingem o nível de incompetência no grau mais baixo e nunca são promovidos. Alguns, como o sr. Círculo (fazendo de conta que não é um bom mestre), alcançam-no após uma promoção.

E. Tinker, o chefe da oficina de consertos, chegou a seu nivel de incompetência no terceiro estágio da hierarquia.

\section{A LEI DE PETER}

Dessa maneira minha análise de centenas de casos de incompetência ocupacional levaram-me a formular A LEI DE PETER:

NUMA HIERARQUIA TODOS OS EMPREGADOS TENDEM A ELEVAR-SE ATÉ SEU NIVEL DE INCOMPETENCIA.

Tendo formulado o princípio, descobri que inadvertidamente achei uma nova clência, a hierarcologia, estudo das hierarquias.

O têrmo "hierarquia" era originàriamente usado para descrever o sistema de govêrno eclesiástico por sacerdotes escalonados em postos. 0 sentido contemporâneo inclui qualquer organização cujos membros ou empregados são dispostos em ordem de pôsto, grau ou classe.

Hierarcologia, embora uma disciplina relativamente recente, parece ter grande possibilidade de aplicação nos campos da administração pública e privada.

\section{Isto se refere a você!}

Meu princípio é a chave para o entendimento de todos os sistemas hierárquicos, e portanto para a compreensão da estrutura total da civilização. Uns poucos excêntricos tentam evitar envolver-se com as hierarquias, mas todos que estão no comércio, na indústria, nos sindicatos, na política, no govêrno, nas fôrças armadas, na religião e na educação acabam sendo. Todos são controlados pela Lei de Peter.

Muitos dêles, para sermos exatos, podem lograr uma promoção ou duas, mudando de um nível de competência para outro mais elevado. Mas a competência naquela nova posição os qualifica para outra promoção ainda. Para cada indivíduo, para você, para mim, a promoção final será de um nível de competência para outro de incompetência.

Assim, dado tempo suficiente - e pressupondo a existência de suficientes postos na hierarquia - cada empregado sobe até seu nivel de incom- 
petência e ali permanece. O Corolário de Peter declara:

Com o tempo, todos os postos tendem a ser ocupados por um empregado que é incompetente para dar conta de seus deveres.

Raramente você encontrará, é claro, um sistema no qual todos os empregados tenham alcançado seu nível de incompetência. Em muitos casos, alguma coisa está sendo feita para facilitar os propósitos ostensivos pelos quais a hierarquia existe.

o trabalho é feito pelos empregados que ainda não alcançaram seu nível de incompetência.

\section{APARENTES EXCEÇס̃ES}

Muitas pessoas a quem mencionei a Lei de Peter não querem aceitá-la. Ansiosamente procuram - e às vêzes pensam que encontraram - faIhas em minha estrutura hierarcológica. Assim, neste ponto, quero fazer uma advertência: Não se deixe enganar por exceções aparentes.

\section{A SUBLIMAÇÃO PERCUSSORA}

"E a respeito da promoção do Walt Blockett? Êle era irremediàvelmente incompetente, um pêso morto, então a direção chutou-o escada acima para tirá-lo do caminho".

Freqüentemente ouço tais perguntas. Vamos examinar o fenômeno que chamei de sublimação percussora (percussive sublimation). Blockett mudou-se de uma posição de incompetência para outra de competência? Não. Êle simplesmente fol transferido de uma posição improdutiva para outra. Agora êle empreende alguma responsabilidade maior que antes?
Não. Acaso êle realiza mais trabalho na nova posição do que na velha? Não.

A sublimaçăo percussora é uma pseudopromoção. Alguns empregados tipo-Blockett de fato acreditam que receberam uma promoção genuína; outros reconhecem a verdade. Mas a principal função da pseudopromoção é enganar pessoas que estão fora da hierarquia. Quando isto é conseguido, a manobra é tida como vitória.

Mas o hierarcólogo experimentado nunca será enganado. Hierarcològicamente, a única mudança que podemos aceitar como promoção genuína é a mudança de um nivel de competência.

A hierarcologia nos ensina que tôda organização próspera é caracterizada por esta acumulação de pesos mortos no nível da direção, composta de sublimados percussores e candidatos potenciais à sublimação percussora. Uma firma de fabricação de ferramentas muito conhecida tem 25 vice-presidentes!

\section{O ARABESCO LATERAL}

$O$ arabêsco lateral é outra pseudopromoção. Sem ser elevado em pôsto - algumas vêzes mesmo sem elevação de pagamento - o empregado incompetente recebe um título nôvo e maior e é transferido para um escritório numa parte remota do estabelecimento.

\section{Arquivo de Manufaturas} Automotivas, caso n? 8.

Wheeler Automobile Parts, Ltd. desenvolveu 0 arabêsco lateral mais completamente que muitas hierarquias. As operações da Wheeler estão divididas em muitas regiões e, em última 
análise, descobri que 25 dirigentes mais antigos tinham sido banidos para o interior como vice-presidentes regionais.

A companhia comprou um motel e ordenou a um antigo funcionário que fôsse dirigi-lo.

Outro vice-presidente supérfluo tem estado trabalhando há três anos para escrever a história da companhia.

Concluo que quanto maior a hierarquia, mais fácil o arabêsco lateral.

\section{INVERSÃO DA LEI DE PETER}

Uma vez, fazendo o professorado numa universidade, recebi um cartão especial de identificação, emitido pelo Departamento Contábil da Universidade, qualificando-me para descontar cheques na livraria da Universidade. Fui à livraria, mostrei meu cartão, e apresentei um "traveler's check" de vinte dólares da American Express.

"Nós recebemos apenas cheques de fôlha de pagamento ou cheques pessoals", disse o caixa da livraria.

"Mas êste é melhor que um cheque pessoal", disse. "E melhor ainda que um cheque da fôlha de pagamento. Posso descontar em qualquer loja, mesmo sem êste cartão especial. O "traveler's check" é tão bom quanto dinheiro."

"Mas não é um cheque da fôlha de pagamento, nem um cheque pessoal", disse o caixa.

Depois de discutir mais um pouco, pedi para ver o gerente. Êle me ouviu pacientemente, mas com ar distante, e em seguida declarou peremptòriamente: "Não descontamos "traveler's checks".
Você já deve ter ouvido de hospitais que gastam tempo precioso preenchendo pilhas de formulários antes de atender vítimas de acidente. Você já ouviu falar de enfermeiras que dizem, "Acorde! Está na hora de tomar sua pílula contra insônia!"

Especialmente entre funcionários inferiores sem podêres discricionários, percebe-se um interêsse obsessivo em fazer com que as formas sejam observadas corretamente, quer as mesmas sirvam a algum propósito útil, quer não. Nenhum desvio, ainda que mínimo, da rotina costumeira, é permitido.

\section{Automatismo Profissional}

O tipo de comportamento acima chamo de automatismo profissional. Para o autômato profissional é claro que os meios são mais importantes que os fins; a papelada é mais importante que a finalidade para a qual ela foi destinada. Elle já não se vê mais como existindo para servir o público: vê o público como a matéria-prima que serve para sustentar a êle, às formas, aos rituais e à hierarquia!

O autômato profissional, do pontode-vista dos seus fregueses, clientes ou vítimas, parece incompetente. Então você, sem dúvida, ficará imaginando: Como é que tantos autômatos profissionais conseguem promoção? E o autômato profissional está fora do domínio da Lei de Peter?

Para responder a estas perguntas preciso antes fazer outra: "Quem define competência?"

\section{Questão de Padrões}

A competência de um empregado é determinada não pelos que estão fora, mas por seu superior na hierarquia. Se 
- superior ainda está num nível de competência, poderá avaliar seus subordinados em têrmos de desempenho, de trabalho útil - por exemplo, o fornecimento de serviços médicos ou informações, a produção de salsichas ou pernas de mesas ou a consecução de sejam quais forem os objetivos declarados da hierarquia. Isto quer dizer que êle avalia rendimento.

Mas se o superior alcançou seu nivel de incompetência, provàvelmente apreciará seus subordinados em têrmos de valôres institucionais: verá competência no comportamento que mantém as regras, rituais e fórmulas dò "status quo". Diligência, esmêro, cortesia para com os superiores, o papelório interno - seräo altamente considerados. Em resumo, êle avalia contribuição.

"Rockman é digno de confiança."

"Lubrik contribui para o andamento suave do escritório."

"Rutter é metódico."

"A senhorita Trudgen é uma trabalhadora firme e sólida."

"A Sra. Friendly coopera bem com os colegas."

Em tais exemplos a consistência interna é valorizada mais altamente que o serviço eficiente: isto é a Inversão da Lei de Peter. O autômato profissional pode também ser chamado de Inverso de Peter. Elle inverteu a relação meios-fim.

Agora você pode entender as ações dos Inversos de Peter descritas antes.

Se o caixa da livraria tivesse aceltado meu "traveler's check", eu o teria considerado prestativo. O gerente tê-lo-ia repreendido por ter excedido sua, autoridade.

\section{Perspectivas de Promoção} para os Inversos de Peter.

O Inverso de Peter, ou autômato profissional, tem, como vimos, pouca capacidade para julgamento independente. Êle sempre obedece, nunca decide. Isto, do ponto-de-vista da hierarquia, é competência, então o Inverso de Peter é elegivel para promoção. Continuará a subir a não ser que alguma fatalidade o coloque num pôsto onde tenha de tomar decisões. Al, êle encontrará seu nível de incompetência.

Vemos portanto que o automatismo profissional - ainda que você o tenha achado aborrecido - não é, afinal, exceção à Lei de Peter. Como sempre digo a meus alunos: "A Competência, como a Verdade, a Beleza e lentes de contacto, está no ôlho do observador."

\section{ESFOLIAÇÃO HIERÅRQUICA}

Em seguida discutirei um caso que aos observadores destreinados talvez seja o mais espantoso de todos: o caso do trabalhador brilhante, produtivo que não apenas não consegue promoção, mas é mesmo destituído do seu pôsto.

Deixe-me dar alguns exemplos, então explicá-los-ei.

$\mathrm{Na}$ Cidade Excelsior todos os novos professôres primários (mestres-escola) passam por um ano de prova. K. Buchman tinha sido um brilhante aluno de inglês na Universidade. No seu ano de experiência como professor de inglês, agiu de modo a infundir nos seus alunos seu próprio entusiasmo pela literatura clássica e moderna. Alguns dêles obtiveram cartões de inscrição na Biblioteca Pública da $\mathrm{Ci}$ dade Excelsior; alguns começaram a 
escarafunchar livrarias e sebos. Ficaram tão interessados que leram muitos livros fora da lista de Leituras Permitidas para as Escolas de Excelsior.

Não demorou muito e alguns pais irados e delegações de duas austeras seitas religiosas visitaram o superintendente da escola para queixar-se de que seus filhos estavam estudando literatura "indesejável". Buchman foi informado de que seus serviços não seriam requisitados no ano seguinte.

A senhorita E. Beaver, uma professôra primária em período experimental, era altamente dotada intelectualmente. Sendo inexperiente, pôs em prática o que havia aprendido na $\mathrm{Fa}$ culdade a respeito de fazer concessões às diferenças individuais entre os alunos. Como resultado, seus alunos mais vivos terminaram dois ou três anos de estudo em apenas um.

O diretor foi muito cortês quando explicou que a srta. Beaver não poderia ser recomendada para contratação permanente. Ele tinha certeza de que ela entenderia que havia transtornado o sistema, não se prendeu ao currículo escolar e criou problemas pa$\mathrm{ra}$ as crianças que não iriam encaixar-se no programa do próximo ano. Ela rompeu o sistema oficial de dar notas e o sistema de edições de livros de texto e causou grave inquietação ao professor que no próximo ano teria de lidar com crianças que já haviam completado o programa.

\section{Explicação do Paradoxo}

Estes casos ilustram o fato de, em muitas hierarquias, a supercompetência ser mais repreensivel que a incompetência.

A incompetência comum, como vimos, não é motivo para despedida: é simplesmente um entrave à promoção. Supercompetência freqüentemente leva à demissão, porque rompe a hierarquia, e dessa forma viola o primeiro mandamento da vida hierárquica: a hierarquia tem de ser preservada.

Os empregados pertencem a cinco classes.

Os das classes extremas - supercompetentes e superincompetentes são igualmente sujeitos à demissão. Costumeiramente são despedidos logo após terem sido empregados, pela mesma razão: êles tendem a romper a hierarquia. $O$ desbastamento dos extremos é chamado esfoliação hierárquica.

\section{Um Exemplo Formidável}

Já descrevi o destino de alguns empregados supercompetentes. Eis agora um exemplo de superincompetência.

A srta. Saucier fol empregada como vendedora na seção de utensílios da Loja Lomark. Desde o comêço ela vendeu menos que a quantidade média de mercadorias. Sòmente isto não teria sido motivo para demissão, pois muitos outros vendedores estavam abaixo da média. Mas os antecedentes da srta. Saucier eram terriveis: apertava as teclas erradas na caixa registradora, aceitava cartões de crédito dos concorrentes e - pior ainda - colocou papel carbono com o lado errado para cima quando preenchia um formulário de contrato de venda. Daí deu um jeito de entregar ao freguês o original do contrato. Êle fol-se com as duas vias (uma na frente da fôlha e outra, invertida, no verso) e ela acabou ficando sem nenhuma. 
Mas pior de tudo é que era insolente com seus superiores. Foi despedida dentro de um mês.

O esfoliado superincompetente deve ter duas características importantes:

1. Êle não consegue produzir (output)

2. Êle não consegue sustentar a consistência interna da hierarquia (input)

\section{Esfoliação é o seu Caso?}

Vemos então que a supercompetência e a superincompetência são igualmente censuráveis pela hierarquia típica.

Vemos, também, que os esfoliados hierárquicos, como todos os outros empregados, estão sujeitos à Lei de Peter.

Diferem dos demais por serem os únicos tipos que, sob as condições presentes, estão sujeitos à demissão.

Você gostaria de estar em outro lugar? Sua atual localização no serviço militar, na escola ou no comércio foi escolhida por você ou você é vítima de pressão legal ou da família? Com planejamento e determinação você, também, pode tornar-se ou supercompetente ou superincompetente.

\section{A MÃO PATERNA}

Alguns proprietários de emprêsas familiares antiquadas costumavam tratar seus filhos como empregados normais. O rapaz começava na base da hierarquia e subia de acôrdo com a Lei de Peter. Aqui, naturalmente, o amor do proprietário pela sua hierarquia, seu desejo de mantê-la eficiente e lucrativa, e seu severo sentimento de justiça contrabalançavam suas naturais afeições familiares.
Freqüentemente, no entanto, o proprietário de tal negócio trazia seu filho até um alto nível, com a idéia de que, com o tempo, sem galgar os postos, êle poderia assumir o comando supremo ou, como se diz, "calçar os sapatos do pai".

Este tipo de colocação, portanto, chamo de a "mão paterna".

Há dois meios principais pelos quais a mão paterna é executada. Um empregado efetivo pode ser demitido ou removido pelo arabêsco lateral ou por sublimação percussora para dar lugar ao "penetra". Ou, mais comumente, uma nova função, com título expressivo, é criada para o novato.

\section{A Explicação do Método}

A mão paterna é meramente um exemplo em escala menor da situação que existe sob o sistema de castas, onde alguns indivíduos favorecidos entram numa hierarquia por cima da barreira de classe, ao invés de pelo princípio da hierarquia.

A admissão de novos empregados num alto nivel pode algumas vêzes aumentar a produção. A mão paterna, portanto, não desperta mal-estar fora da hierarquia.

No entanto, a chegada do "penetra" provoca, em certo grau, ressentimento nos outros membros da hierarquia. $\mathrm{Na}$ realidade, os empregados têm suscetibilidade sentimental (Tendência de Peter) pelo processo de promoção pelo qual êles próprios subiram e esperam subir mais. Tendem a ressentir-se de colocações feitas por outros meios.

O negócio familiar, controlado por um homem com autoridade para colocar seus filhos nos mais altos postos, é, hoje em dia, quase raridade. Toda- 
via, a mão paterna ainda é executada do mesmo modo, apenas o novato não precisa ser parente do funcionário que 0 indica.

Deixe-me citar um exemplo típico.

\section{Arquivo de Mão Paterna,} caso $n ? 7$

A. Purefoy, Diretor do Departamento de Saúde e Higiene da Cidade Excelsior, descobriu que ao final do ano financeiro teria alguns fundos inesperados. Os cidadãos não tinham sofrido epidemias; o rio Excelsior não tinha, como sempre fazia, transbordado do leito e obstruido o sistema de drenagem; ambos os diretores assistentes (um para saúde e outro para higiene) eram homens de mentalidade econômica, zelosos e competentes.

Assim sendo, os fundos orçamentários não tinham sido gastos. Purefoy percebeu que, se não entrasse imediatamente em ação, sofreria um corte no orçamento do ano vindouro.

Decidiu criar uma terceira diretoria assistente cuja incumbência fôsse organizar um Programa de Anti-Sujeira e de Embelezamento. Para preencher o nôvo cargo êle contratou W. Pickwick, jovem diplomado da Faculdade de Administração de Emprêsas da sua própria universidade.

Pickwick, por sua vez, criou onze novos postos: um supervisor anti-sujeira, seis inspetores de sujeira, uma equipe de três garôtas e um secretário de relações públicas.

N. Wordsworth, o S.R.P. 1, organizou concursos escolares de redação, concurso de "jingles" 2 e de cartazes, para adultos, e encomendou dois filmes, um de propaganda anti-sujeira e outro sôbre embelezamento da cidade. Os filmes deveriam ser feitos por um produtor particular que tinha estado no Grêmio Dramático Universitário com Wordsworth e Pickwick.

Tudo funcionou bem: o Diretor Purefoy ultrapassou seu orçamento e teve êxito na obtenção de maiores verbas para o próximo ano. 3

\section{Substitutos Modernos do Pai}

Hoje em dia, os governos ampliaram a situação do "sapato do pai". Concessões federais são oferecidas para muitas finalidades novas - Guerra à Poluição, Batalha contra a Sujeira, Luta contra o Analfabetismo, Combate à Solidão, Campanha pelos Filhos Naturais e pesquisas quanto aos Potenciais Recreativos das Viagens Interplanetárias para os Menos Favorecidos Culturalmente.

Tão logo é oferecido dinheiro, um caminho precisa ser encontrado para gastá-lo. Um nôvo cargo é criado Coordenador da Antipoluição, Diretor de Alfabetização, Conselheiro de Seleção de Livros, Organizador dos Projetos da Felicidade e Bem-Estar dos Cidadãos mais Velhos ou $O$ Que Quer Que Você Imagine. Alguém é convocado para ocupar a posição e para usar, se não fôr apenas para preencher, os sapatos.

1. N.T. - S.P.R. - Secretário de Relaçōes Públicas.

2. N.T. - "Jingles", literalmente - rima. Săo os anúncios curtos, gravados em discos que sáo "martelados" pelo rádio.

3. N.T. - Evidentemente, o exemplo năo se aplica ao Brasil Grande, uma vez que a nova mentalidade orçamentária impede êsses descalabros tăo comuns no passado. 
O "penetra" pode ou não resolver o problema que fol incumbido de solucionar. Isto não importa. O ponto importante é que deve ser capaz, e ter desejo de gastar o dinheiro reservado.

Tal situação está de acôrdo com a Lei de Peter. Competência ou incompetência é irrelevante desde que os sapatos estejam preenchidos. Se forem preenchidos competentemente o "penetra" será com o tempo elegivel para subir e, saindo dêles, encontrar seu nível de incompetência num plano mais elevado.

\section{CONCLUSÃO}

As exceções aparentes não são exceções. A Lei de Peter se aplica a todos os empregados em tôdas as hierarquias. 